\title{
La fábula del ratón de campo y el ratón de ciudad y el monólogo de Areúsa sobre la vida de las criadas ${ }^{1}$
}

\author{
Rafael Beltrán \\ Universitat de València
}

No ha sido hasta el momento señalada - que yo conozca - la posible presencia de una huella, o al menos un eco de la fábula del ratón de campo y el ratón de ciudad (ATU, 112: Country Mouse Visits Town Mouse), en el monólogo de Areúsa sobre la vida de las criadas, que se da al final de la segunda escena del noveno auto de La Celestina. Un simple eco significaría una apenas audible resonancia sonora, una escueta alusión o una repetición intertextual, sin mayor significación o trascendencia. Pero una huella, en cambio, ahonda lo suficiente como para afectar al sentido del fragmento en el que el eco reverbera, repercute y se difunde. Y es esto segundo lo que a mi juicio ocurre en el monólogo, donde la presencia con sentido de un eco - la acústica que deja el cuento de los dos ratonesimprime una huella más profunda, que, si se capta, puede contribuir a la mejor intelección de las palabras y del papel que desempeña el personaje que las enuncia.

Se informa de la llegada de Lucrecia a la casa de Celestina, donde comen, beben y dialogan - discutiendo, riendo, llorando- Celestina, Areúsa, Elicia, Sempronio y Pármeno. Y esa llegada da pie a un largo parlamento de Areúsa. Los monólogos, propone Lida de Malkiel, caracterizan a los personajes de La Celestina mejor que los diálogos, en parte "por la luz que proyectan sobre la intimidad de las almas, que de ninguna manera se exhiben con igual franqueza en el diálogo» (1966: 124). Así ocurre en el extenso monólogo de Areúsa, uno de los doce que jalonan la obra, donde ésta identifica la vida de las criadas de servicio doméstico, como Lucrecia, con la necesidad de verse obligadas a aceptar la arbitraria opresión a la que las someten de sus señoras. Peter Russell sintetiza el sentido del pasaje: «Esta larga y genial diatriba de Areúsa contra las señoras y su

1.- El presente artículo ha sido elaborado dentro del marco del Proyecto de Investigación FFI2011-25429, financiado por el Ministerio de Economía y Competitividad del Gobierno de España. 
manera de tratar a sus criadas, amplificada en la TC [Tragicomedia], sigue otra vez de cerca el vivo y apresurado estilo conversacional de las mujeres de pueblo del Arcipreste de Talavera. Al mismo tiempo que comento social, subraya el pasaje el carácter abierto e independiente de la ramera, que prefiere vivir "esenta y señora» y no «sojuzgada» como criada en palacio de ricos» (Rojas, 1991: 414-415).

Reparemos en que el monólogo de Areúsa se cierra con la siguiente conclusión:

Por esto, madre, he querido más vivir en mi pequeña casa, esenta y señora, que no en sus ricos palacios, sojuzgada y cativa. ${ }^{2}$

Esta frase comparativa, que tiene una estructura muy formalizada, con ecos claros de sintaxis de paremia (paralelismo en los dos sintagmas de adjetivo + sustantivo, y en las parejas de adjetivos coordinados y apuestos al sujeto), es el corolario contundente - enunciado desde la firmeza, pues no estamos ante un monólogo dubitativo, como otros de Calisto o Sempronio (De Miguel, 1996: 170-183) — con el que culmina una amplificación temática en torno al motivo del quehacer cotidiano de esas jóvenes. Motivo que acaba de ser expuesto, en cambio, y paradójicamente, por la misma enunciante, Areúsa, de manera en apariencia desordenada o deshilachada. Y ese buscado desorden, en el que la crítica ha destacado, como acabamos de ver resumido en la nota de Russell, el modelo del estilo vivaz, enérgico y coloquial de los parlamentos femeninos del libro II del Arcipreste de Talavera, viene del deseo de plasmar no una estricta argumentación que conduzca a la comprensión lógica, sino una explosión afectiva y sincopada de emociones y sensaciones. Areúsa habla de una cuestión que le atañe directamente, le ha afectado en su pasado y le incumbe todavía con toda probabilidad en el presente - si no a ella, a las muchachas a su alrededor-; le emociona y conmueve tanto que no sabe exponer sino de manera apasionada y por ello algo irracional. Su torrente de enunciados, que se exponen con sintaxis paratáctica, remitiendo, como hacía con evidentes logros la prosa del Arcipreste, a la emulación de una o varias voces físicas y concretas, individualizadas, y utilizando elementos y fuentes aún por descubrir en parte -además de la innegable de Alfonso Martínez de Toledo-, exige en todo caso, para su desenlace una recapitulación lógica, clara y rotunda, que concentre las virtualidades significativas y abstractas en una máxima de valor general y universal. Y eso es lo que la propia Areúsa facilita con esas dos líneas paremiológicas conclusivas.

Trataré de defender que Areúsa está recogiendo en esta paremia o sentencia última ("he querido más vivir en mi pequeña casa, esenta y señora, que no en sus ricos palacios, sojuzgada y cativa») el eco del final de 
la famosa fábula esópica, cuando el ratón de campo, escarmentado por su traumática experiencia de visita a la casa del ratón de ciudad, expresa su preferencia por las humildes y parcas comodidades de la vida aldeana y su desprecio por las peligrosas delicias urbanas. ${ }^{3}$ Y que esa repetición acústica, como he comentado, tiene que actuar aquí como algo más que simple resonancia y ha de tener un mayor sentido. De hecho, confirmarán ese eco paremiológico y lo reforzarán las palabras de la propia Celestina. Esta, en su réplica nada más acabar de hablar Areúsa, suscribe los inapelables elogios a la libertad que acaba de hacer la muchacha - verdadera alabanza de aldea o, en su caso, en esa sentencia final, de "pequeña casa», con menosprecio de corte o de «ricos palacios»-y clausura el marco de la escena. Y lo hace utilizando otra sentencia (autorizada por «los sabios»), con nuevo paralelismo codificado y con presencia ahora sí ya claramente- de la metáfora gastronómica de la fábula, que no se explicitaba en la frase de Areúsa:

En tu seso has estado; bien sabes lo que haces, que los sabios dicen que vale más una migaja de pan con paz que toda la casa llena de viandas con rencilla.

\section{El monólogo sobre la vida de las criadas}

Pero, antes de justificar nuestra hipótesis sobre la presencia de la fábula en el pasaje, recordemos el contexto del auto IX, a partir de su argumento:

Sempronio y Pármeno van a casa de Celestina entre sí hablando. Llegados allá, hallan a Elicia y Areúsa. Pónense a comer, y entre comer riñe Elicia con Sempronio. Levántanse de la mesa. Tórnanla a apaciguar. Estando ellos todos entre sí razonando, viene Lucrecia, criada de Melibea, a llamar a Celestina que vaya a estar con Melibea. (Rojas 2011: 201)

La llegada de Lucrecia, criada de Melibea en la casa de Alisa, marcará una ruptura, un contraste frente a la conversación que vienen manteniendo los cuatro jóvenes con Celestina -igualados los cinco personajes socialmente-, sobre temas varios que les afectan de manera directa, como

3.- No aparecen, en principio, desde luego, ni siquiera en el monólogo de Areúsa, ratas ni ratones que se pudieran relacionar con la fábula mencionada, aunque se presentan otras menciones de ratas o ratones en La Celestina y la más notable es precisamente una alusión a otra fábula, la del elefante y el ratón (Blay \& Severin 8, 9, 18, 29 y 31). Añádase que en el mismo inicio del auto IX, compara Sempronio a Celestina con una rata, sin mencionar al animal, pero sí su labor de roedor: "Cuando hay qué roer en casa, sanos están los santos; cuando va a la iglesia con sus cuentas en la mano, no sobra el comer en casa» (Rojas, 2011: 201). Véase, específicamente para las fábulas sobre ratones en la Edad Media, Refael-Vivante (2009). 
la mocedad, el amor y los celos. ${ }^{4}$ Avisan de esa disparidad —la distinta condición de Lucrecia, aun dentro de la homogeneidad de clase, es evidente (Maravall, 1981: 86-87)—, las palabras de presentación de Celestina:

Ábrele, y entre ella, y buenos años, que aun a ella algo se le entiende desto que aquí hablamos, aunque su mucho encerramiento le impide el gozo de su mocedad.

A Areúsa le bastarán las palabras introductorias de la «madre» Celestina, que apuntan certeramente en la diana de la principal diferencia entre Lucrecia y la pareja que forman Elicia y ella misma, para dar rienda suelta, con suficiente aliento y pleno sentido, a un despecho y desprecio que se había conformado antes con limitar a unos juicios grotescos sobre el físico de Melibea (Rojas, 2011: 206-207). Ahora, sin embargo, se van a generalizar, aplicados a toda una clase social señorial:

AreúsA. Así goce de mí, que es verdad que estas que sirven a señoras ni gozan deleite ni conocen los dulces premios del amor. Nunca tratan con parientas, con iguales a quienes puedan hablar tú por tú, con quien digan: «¿Qué cenaste?», «¿Estás preñada?», «¿Cuántas gallinas crías?», "Llévame a merendar a tu casa», "Muéstrame tu enamorado", "¿Cuánto ha que no te vido?», "¿Cómo te va con él?», "¿Quién son tus vecinas?»y otras cosas de igualdad semejantes. ¡Oh tía, y qué duro nombre y qué grave y soberbio es "Señora" contino en la boca! Por esto me vivo sobre mí desde que me sé conocer. Que jamás me precié de llamarme de otrie sino mía, mayormente destas señoras que agora se usan. Gástase con ellas lo mejor del tiempo, y con una saya rota de las que ellas desechan pagan servicio de diez años. Denostadas, maltratadas las traen, contino sojuzgadas, que hablar delante ellas no osan. Y cuando ven cerca el tiempo de la obligación de casallas, levántanles un caramillo: que se echan con el mozo o con el hijo, o pídenles celos del marido, o que meten hombres en casa, o que hurtó la taza o perdió el anillo. Danles un ciento de azotes y échanlas la puerta fuera, las haldas en la cabeza, diciendo: "iAllá irás, ladrona, puta, no destruirás mi casa y honra!». Así que esperan galardón, sacan baldón; esperan salir casadas, salen amenguadas; esperan vestidos y joyas de boda, salen desnudas y denostadas. Éstos son sus premios, éstos son sus beneficios y pagos. Oblíganse a darles marido,

4.- La presentación de Lucrecia como personaje independiente ha sido estudiada, entre otros, por Eaton (1973), Lacarra (1990) y Beltrán (1997). 
quítanles el vestido. La mejor honra que en sus casas tienen es andar hechas callejeras, de dueña en dueña, con sus mensajes a cuestas. Nunca oyen su nombre propio de la boca dellas, sino "Puta» acá, "Puta» acullá. "¿Adó vas, tiñosa?», ¿Qué heciste, bellaca?», "¿Por qué comiste esto, golosa?», "¿Cómo fregaste la sartén, puerca?», «¿Por qué no limpiaste el manto, sucia?», "¿Cómo dijiste esto, necia?», "Quién perdió el plato, desaliñada?», "Cómo faltó el paño de manos, ladrona? A tu rufián le habrás dado». "Ven acá, mala mujer, ¿̇la gallina habada no parece?, pues ¡búscala presto!; si no, en la primera blanca de tu soldada la contaré». Y tras esto, mil chapinazos y pellizcos, palos y azotes. No hay quien las sepa contentar, no quien pueda sofrirlas. Su placer es dar voces, su gloria reñir. De lo mejor hecho menos contentamiento muestran. Por esto, madre, he querido más vivir en mi pequeña casa, esenta y señora, que no en sus ricos palacios, sojuzgada y cativa. (Rojas, 2011: 212-213) ${ }^{5}$

Se trata de un denso monólogo, bien "coloreado" retóricamente, donde Areúsa, con una facundia y una acritud notables, que podrían parecer un tanto exageradas o desproporcionadas en ese contexto, exhibe una amplia paleta de recursos cromáticos, pero lo hace desde una perspectiva muy concreta. El caso particular del "mucho encerramiento» que impide a Lucrecia «el gozo de la mocedad", tal y como ha diagnosticado agudamente Celestina, da paso a un torrencial despliegue de sofisticada amplificación. Tal despliegue contiene una ejemplificación o visualización - hipotipesis o evidentia retórica - de lo que significa la condición servil de criadas y la privación de libertad que implica el servicio doméstico en casa de "señoras» (Parrilla, 1999). La evidentia es una puesta en escena, física y en presente, y esa escenificación en vivo se lleva a cabo aquí mediante la simulación de una voz o diversas voces que profieren insultos, ataques o denuestos y que dejan efectivamente en "evidencia» lo que supone de martirio la vida con esas desagradecidas y miserables amas que "con una saya rota de las que ellas desechan pagan servicio de diez años». El monólogo de Areúsa se desborda, por tanto, porque pasa de ser simple opinión sobre un caso específico, el «encerramiento» de Lucrecia, a disquisición generalizada sobre las causas y efectos de ese "encerramiento» involuntario, que la totalidad de su clase ha de asumir como una condena

5.- Desde "nunca tratan con parientes», en la segunda línea, hasta "contino en la boca», cuatro o cinco líneas más adelante, es añadido de la Tragicomedia. Para el texto de la Comedia, véase Canet (2011: 287-288), que anota al pie el añadido de las eds. de Zaragoza (Jorge Coci, 1507) y Valencia (Juan Joffré, 1514). Tengo presentes también las ediciones de Severin (Rojas, 1995) y Morros (Rojas, 1996). 
a prisión. Sus palabras se pueden leer, así, como una proyección al conjunto de las criadas - al gremio de las mujeres que desempeñan servicio doméstico- de las palabras que Celestina acababa de aplicar de manera certera a solamente una de ellas. ${ }^{6}$

El discurso ofrece, a nivel dispositivo y elocutivo, como los mejores fragmentos de La Celestina, una auténtica mina de artificios de elocución sabiamente entreverados. ${ }^{7}$ Areúsa, que acepta y recoge el testigo del juicio experto de Celestina sobre la inferioridad de la criada debida a su encierro, amplifica el tema, poniendo en juego una serie de situaciones - actos de habla - en las que se contraponen los enunciados (supuestamente equiparables) que emiten las distintas enunciantes o grupos de enunciantes desde posiciones y clases sociales diametralmente opuestas. La falta de libertad de las criadas se "visualiza» haciendo constar una patente carencia de oportunidades para hablar. Las jóvenes esclavizadas en el servicio doméstico no pueden emplear expresiones naturales y espontáneas, las de una conversación normal, habitual, entre iguales, de «tú» a "tú»:

Nunca tratan con parientas, con iguales a quien puedan hablar tú por tú, a quien digan: "Qué cenaste?», "¿Estás preñada?», "¿Cuántas gallinas crías?», «Llévame a merendar a tu casa", "Muéstrame tu enamorado» [...] «¿Quién son tus vecinas?» y otras cosas de igual semejantes.

Ni siquiera gozan de esos sencillos placeres del día a día. Como dice García Yero:

Para Areúsa, la inferioridad de la criada se asienta sobre la falta de libertad para amar y para hablar. [...] La libertad e igualdad en la participación comunicativa es considerada esencial, y su ausencia en la relación amo / criado constituye uno de los males medulares, hasta el punto de que apenas se habla en dicho parlamento de las limitaciones de una criada para el goce erótico; lo que más atrae la elocuencia y el rencor de Areúsa es el silenciamiento, la imposibilidad de desempeñar un rol

6.- Aunque no se mencione para nada el dinero, de algún modo la lección podrá ser aprovechada para todo el grupo o clase de «siervos comprados» o "siervos salariados» (Maravall, 1981: 92).

7.- Serés (2007: 400-401) lo pone como ejemplo de ornato retórico y demuestra, a través de reveladores subrayados con negritas y cursivas, la utilización profusa pero bien contrapesada de recursos de paralelismos y contrastes. Así, por ejemplo, duplicaciones léxicas y sintácticas (estructuras bimembres, correlaciones, geminaciones, etc.): "gozan deleite» / "conocen los dulces premios del amor», "parientas» / «iguales», "a quien puedan hablar» / "con quien digan», «denostadas» / "maltratadas» / «sojuzgadas», "desnudas» / "denostadas», "chapinazos y pellizcos» / "palos y azotes», "placer» / "gloria», «sojuzgada» / "cativa»; o paralelismos y antítesis: «danles», «échanlas», «baldón» / "galardón», "casadas» / "amenguadas», «oblíganse» / «quítanles», «no hay quien» / «no quien», «mejor» / «menos». 
interlocutivo cabal, la pérdida, incluso, del sello participativo fundamental del ser humano, es decir, el nombre propio. (2003: 31)

Esa cotidianeidad familiar, franca, tan natural y necesaria en el habla de las muchachas, casi niñas, y que habría de ser la habitual y estar normalizada, es sustituida por el habla dominante y opresiva, acusadora e insultante, amenazante y arbitraria de sus amas, que Areúsa imita a continuación, en el mismo monólogo, cambiando naturalmente de registro enunciante:

«Puta» acá, «Puta» acullá. "¿Adó vas, tiñosa?», ¿Qué heciste, bellaca?», «¿Por qué comiste esto, golosa?», "¿Cómo fregaste la sartén, puerca?», "¿Por qué no limpiaste el manto, sucia?», «¿Cómo dijiste esto, necia?»

Tienen pleno sentido los nuevos periodos en el discurso (vocativo insultante más demostrativo deíctico; interrogación inquisitiva más vocativo), paratácticos y simétricos, no sólo breves, sino afilados y punzantes. Como señala Bustos, al referirse a este pasaje: «lo específicamente coloquial está fuertemente influido por lo retórico» (2001: 198). Cada insulto parece un ladrido, pronunciado por la mujer "parlera», vulgar, en que se convierte esa supuesta "señora» cuya habla se imita. Ladridos como los que se dice que profiere la mujer "parlera» ("virlingosa»), cuando pierde un huevo, en el tercer libro del tratado De Amore de Andreas Capellanus, de donde precisamente procede el pasaje que hace suyo el Arcipreste de Talavera. En efecto, da el texto del De Amore:

Est et omnis virlingosa, quia nulla est quae suam noverit a maledictis compescere linguam, et quae pro unius ovi amissione die tota velut canis latrando non clamaret et totam pro re modica viciniam non turbaret.

[También son todas charlatanas, pues no hay ninguna que sepa retener su lengua de soltar imprecaciones. Por la pérdida de un solo huevo no paran de gritar durante todo el día ladrando como perros, y por el motivo más insignificante ya molestan a su vecina.] (Creixell, 1990: 405). ${ }^{8}$

Dice Alfonso Martínez de Toledo, en su Arcipreste de Talavera, que: «Por un huevo dará bozes como loca e fenchirá a todos los de su casa de ponçoña».

8.- Ariza (2003: 113-115) estudia en paralelo el fragmento de la pérdida del huevo y el de la pérdida de la gallina: inicio similar con serie de interrogaciones, maldiciones, elogio de lo robado, más nuevas maldiciones y lamentos; divergencia con amplificación mayor en la secuencia del robo de la gallina; y final de nuevo convergente con invocación a Dios y reflexión del narrador. Véase también Salvador Plans (2007: 338-339). 
De hecho, parte del fragmento del monólogo de Areúsa - la sección de los insultos- se podría leer con diferente puntuación, que subrayara con más énfasis, multiplicando las interjecciones, el papel de las «bozes» o «ladridos»:

*Puta!, ¡acá! ¡Puta! ¡acullá! ¡Adó vas? ¡Tiñosa! ¿Qué heciste? ¡Bellaca! ¿Por qué comiste esto? ¡Golosa! ¿Cómo fregaste la sartén? ¡Puerca! ¿Por qué no limpiaste el manto? ¡Sucia! ¿Cómo dijiste esto? ¡Necia! ¿Quién perdió el plato? ¡Desaliñada! ¿Cómo faltó el paño de manos? ¡Ladrona! A tu rufián le habrás dado.

Es innegable la dependencia del pasaje de La Celestina respecto al soliloquio en torno a la pérdida de la gallina de la estrafalaria mujer de Alfonso Martínez de Toledo. La "gallina» funciona, de hecho, en el monólogo de Areúsa, como elemento culinario de apertura y cierre. Al principio se dice que la criada preguntaría a la "parienta», en una situación normal: "Cuántas gallinas crías?»; y al final se concluye con la acusación de «Ven acá, mala mujer, ¿la gallina habada no parece?...», desde la posición diametralmente contraria y antes de que la criada reciba la lluvia de «mil chapinazos y pellizcos, palos y azotes». El concierto ya de por sí estridente de varios registros que se capta en el soliloquio del Arcipreste de Talavera, emitido sin embargo siempre desde una única voz, se redimensiona en el monólogo de Areúsa al ser observada la pérdida también desde el punto de vista de la inocente acusada, lo que corrobora la sinrazón de la «señora» dominante y avariciosa.

Hay muchos detalles en este monólogo que valdría la pena destacar y analizar, aunque esa exploración nos podría desviar del propósito y objetivo principal en nuestro acercamiento al mismo. No podemos, sin embargo, dejar de comentar, abundando en la densidad y complejidad del fragmento, que en el mismo parlamento de Areúsa hay al menos un par de líneas o tres que parecen aludir a un debate poético juglaresco, como el de Elena y María, al contraponer dos situaciones, la de la muchacha protegida por el militar (Elena, en el debate; Areúsa, en La Celestina) frente a la protegida por el clérigo (María, en el debate, cuyo equivalente sería aquí la "señora» a la que sirve la criada genérica a la que se refiere Areúsa). Marcamos con barra los periodos principales y con cursiva las rimas:

Así que esperan galardón, sacan baldón, / esperan salir casadas, salen amenguadas; / esperan vestidos y joyas de boda, / salen desnudas y denostadas. Éstos son sus premios, éstos son sus beneficios y pagos. / Oblíganse a darles marido, quítanles el vestido.

Cuando María avergüenza a Elena, en el debate, reprochándole las carencias de su amigo "el cavallerón», va siguiendo un esquema que parte 
de (1) la comida y bebida («el pan a raçión / el vino sin sazón», vv. 53-54) con la misma rima en -ón que aquí; sigue con (2) el vestido ("como tray poco vestido / siempre ha fambre e frío", vv. 57-58), aquí marido - vestido; y acaba con (3) el albergue ("Come mal e jaze mal / de noche en su ostal, / ca quien anda en casa ajena, / nunca sal' de pena», vv. 59-62), aquí sustituido por la esperanza de tener casa propia, con el matrimonio. En el mismo triplete (comida y bebida, vestido y hospedaje) ha insistido en versos anteriores María, defendiendo a su amigo el clérigo, con semejantes rimas fáciles y persuasivas: "ha de comer e beber / e en buenos lechos jazer; / ha de vestir e calçar / e bestias en qué cabalgar» (vv. 37-40). ${ }^{9}$

Las rimas internas consonánticas son, en efecto, patentes en el texto celestinesco, como suele destacar los anotadores del pasaje: galardón - baldón, casadas - amenguadas, marido - vestido, desnudas - denostadas. Pero más que el uso de un recurso propio de dichos o refranes, que suelen mencionar los críticos, me parece que los periodos están evocando aquí las rimas de alguno de estos debates juglarescos. Compárese, por ejemplo, como hemos anotado más arriba, "Oblíganse a darles marido, quítanles el vestido", con "como trae poco vestido, siempre ha fanbre e frío» (Elena y María, vv. 57-58). Las consonancias y asonancias sonoras, llamativas, cortantes, con finales en -ío (marido - vestido - frío), son habituales en estos debates, al igual que las agudas, con finales en -ardón /-aldón (galardón, baldón). Pero de nuevo los ecos de los debates entre el clérigo y el caballero, o entre las protegidas de uno u otro, no tendrían mayor importancia si no llevaran tras de sí un significado o connotaciones más hondas. Areúsa le ha dicho a Celestina, cuando ésta va a proponerle que acepte a Pármeno, en la segunda escena del auto vil, que "aquel mi amigo", ese soldado que "se partió ayer [...] con su capitán a la guerra», es decir, su amante, "...me da todo lo que he menester. Tiéneme honrada, favoréceme y trátame como si fuera su señora» (Celestina 2011: 176-177), y ha concretado las bondades de esa relación en que le proporciona comida, calzado, ropa y casa, los mismos ingredientes de subsistencia básica que ahora critica que no tienen a su alcance las otras doncellas. El servicio doméstico —y sexual— demanda la contraprestación de la protección, antes incluso que el pago en prendas o dinero. De ahí que, a mi juicio, las palabras y actitudes de Areúsa puedan también querer emular tácitamente las de la Elena del debate juglaresco, del mismo modo que se estaría comparando con el "cavallerón» dadivoso de este debate a su militar ahora ausente - ausencia que ha aprovechado Celestina para convencerla, no sin resistencia de su parte, de la conveniencia de prestar nuevos servicios a Pármeno-, contraponiendo, por tanto, con nuevas resonancias literarias, a quienes gozan como ella de esa protección, frente a quienes, inermes, no pueden disfrutar de las ventajas de un propicio amparo masculino.

\section{9.- Sigo para el debate la edición y estudio de Franchini (2001: 229-234).}


Resumiendo, Areúsa ha opuesto, con la ayuda de distintos y complejos sustentos retóricos, pero que al cabo trasmiten el mensaje de manera clara y rotunda, dos maneras totalmente enfrentadas (no sólo disímiles) de concebir el mundo: ser criada de señora despótica (como Lucrecia no tiene más remedio que serlo de Alisa, en casa de Melibea, y de ahí su "encerramiento»), o ser ama de una misma; es decir, estar "sojuzgada y cativa» frente a ser "esenta ['libre'] y señora»:

Por eso me vivo sobre mí desde que me sé conocer ['desde que tengo uso de razón']. Que jamás me precié de llamarme de otrie sino mía, mayormente de estas señoras que agora se usan.

\section{El ratón de "pequeña casa» frente al ratón de «rico palacio»}

Areúsa ha utilizado básicamente, para complementar la alabanza la libertad, tutelada por la protección masculina, el campo semántico de la sencillez (mediocritas), con su espacio físico ("pequeña casa» frente a "ricos palacios»), sin necesidad de usar imágenes culinarias. Celestina, sin embargo, reubicará sus argumentos en el terreno de la seguridad y la tranquilidad, utilizando - ella sí- las metáforas gastronómicas de la fábula del ratón de campo y el ratón de ciudad. Habla de pan con «paz» frente a "viandas» con «rencilla», si bien utilizando, como Areúsa, las comparaciones de superioridad ("quiero más...», vale más...»). Volvamos a recordar las palabras conclusivas de Areúsa en su monólogo:

Por eso madre, he querido más vivir en mi pequeña casa, esenta y señora, que no en sus ricos palacios, sojuzgada y cativa.

Y recordemos también, de nuevo, el asentimiento, a renglón seguido, de Celestina, confirmando la postura de su pupila:

En tu seso has estado; bien sabes lo que haces, que los sabios dicen que vale más una migaja de pan con paz que toda la casa llena de viandas con rencilla.

Entendíamos, hasta ahora, esa conclusión de Areúsa como corolario de su argumento, y las palabras de Celestina como coda a las de su pupila, pero ambas en armonía y en plena coherencia con el extenso monólogo. Aunque existen otras posibilidades interpretativas. ${ }^{10}$

10.- Baranda (2004: 168) interpreta, a propósito de estas palabras de Areúsa, que, frente a la radicalidad de la vieja, es coherente con el sentido de moderación y de conformidad con el día a día de las muchachas: «su diatriba contra las señoras en la casa de la alcahueta termina 
Pues bien, se ha señalado, en especial para el segundo enunciado, el de Celestina, su relación con el libro bíblico de los Proverbios, XVII, 1:

Melior est buccella sicca cum gaudio quam domus victimis cum iurgio.

['Mejor es un bocado seco, y en paz, que casa de contiendas llena de provisiones'.]

Y también la relación con varios refranes castellanos. Así, como anotan los más recientes editores:

"Más valen cardos en paz que pollos con agrás» (Seniloquium, 250); «más vale pedazo de pan con amor que gallinas con dolor» (Núñez, 76v); o "Más vale pan solo con paz que pollos con agraz» (Correas, 541). (apud Rojas, 2011: 881)

Hay, sin embargo, bastantes más testimonios, como con meticulosidad prácticamente exhaustiva anotan R. Cantalapiedra y J. Moreno, editores del Seniloquium (2004: 129). Por ejemplo, Covarrubias, 988b, s. v. vaca, da como proverbio, además de la variante citada más arriba, esta otra: "Más vale vaca en paz, que pollos con agraz»; y añade: «del comer los hombres con mucho regalo vienen a empobrecer y a verse en necesidad, cargándose de deudas que no pueden pagar». Y los mismos editores señalan cómo llega hasta otra comedia celestinesca, Lisandro y Roselia (III, II, 97): «BRUMANDILón.- Quiero vivir a mi contento y quítame de revueltas; que a más quiero vaca en paz que pollos con agraz».

Pero es el mismo Gonzalo Correas quien incluye, en la exposición de una de las variantes de refrán, $n^{\circ}$ 13800, la alusión a la fábula esópica del ratón de campo:

Más vale comer grama y abrojo que traer capirote sobre el ojo. / Un ratón de una despensa convidó a otro campesino que se viniese con él a hartar de buenas comidas; hízolo así, y estando ambos comiendo entró el gato, y el ratón de casa, como sabía bien su guarida, escondiose presto; el campesino tardó más, y se vio en peligro; el gato le alcanzó un rasguño sobre el ojo, que fue menester ponerse un pegote. Otra vez después le volvió a convidar, y él, escarmentado de la primera, respondió las pala- 
bras del refrán: aplícase a cosas semejantes, y dice lo que el otro: "Más vale vaca en paz que pollos con agraz». ${ }^{11}$

Correas nos conduce a la relación entre la paremia (refrán, en este caso) y el cuento. El refrán trae a la memoria el cuento del ratón "campesino» y el ratón de ciudad ("de una despensa»). Y el cuento también incluye, a su vez, la paremia o refrán: "le volvió a convidar, y él, escarmentado de la primera [vez], respondió las palabras del refrán»; es decir, respondió: "más vale comer grama y abrojo que traer capirote sobre el ojo».

¿Y antes de Correas, antes de La Celestina? Sin duda eran conocidos paremia o refrán, pero... ¿también la fábula de los dos ratones? Sí, evidentemente. Para Chevalier (1999: 89-91), efectivamente, la fábula tuvo que ser conocida en la Edad Media no solo como cuento erudito, sino como cuento popular. ${ }^{12} Y$ justifica su afirmación precisamente a partir de testimonios como el de Correas y menciones anteriores como la de Juan Ruiz, el Arcipreste de Hita, que vamos a comentar a continuación. Sin embargo, pese a la falsa apariencia de popularidad (porque, siendo apólogo universal, las versiones gráficas y cinematográficas han sido muchas en el siglo $\mathrm{xx}$ ), reconoce igualmente que no sería una de las fábulas más populares, al menos en la tradición hispánica, como tampoco lo siguió siendo posteriormente: «ha dejado pobres huellas en la tradición oral española».13

La rima final es fundamental para captar el desenlace de la fábula, pero también para detectar la popularidad del cuento. No siempre es la rima "paz» / "agraz» la que triunfa. Chevalier destaca que, a partir la versión que presenta Francisco Santos en Periquillo el de las gallineras ("Más quiero comer cardos y abrojos que caperuzas sobre los ojos») la rima de refrán

11.- Véase, para el papel del "gato» en Correas (que incluye su interrelación con el ratón), el estudio de Cazal, que menciona el contexto de este proverbio en particular, así como del cuentecillo aludido (1997: 38).

12.- «No podemos dudar que las aventuras y desventuras del ratón de la corte y del ratón del campo son a la vez fábula erudita, desde el Libro de Buen Amor hasta Samaniego, y cuento folclórico del área de lengua española, recogido antaño por Correas, modernamente por Fernán Caballero, Joaquín Díaz y J. B. Rael, y aprovechado por Francisco Santos en Periquillo el de las gallineras» (Chevalier, 1999: 91). Y ello pese a que el Catálogo de Camarena y Chevalier (1997: 184-185) recoge muy pocas versiones orales: en concreto, cinco castellanas, tres del área lingüística del catalán y una gallega. A las que podríamos añadir otra valenciana, en la que se ha cambiado la pareja de protagonistas por el clásico antagonismo rata / gato (Beltrán, 2007: 120-121); la rata de esta versión es tan lista que contesta con latines cuando el gato le pone una trampa cerca de su escondite. Y añadiríamos, igualmente, una asturiana (Suárez 1998: n 10). Véase, para ambas, más abajo, n. 19.

13.- Chevalier (1999) divide la tradición de los textos conservados con la fábula en dos grupos. El primero derivado directa o indirectamente de la Sátira II de Horacio: la versión de Argensola en su Epístola a don Francisco de Eraso, la de La Fontaine (I, 9) y la de Samaniego (I, 8); en todas ellas falta el gato y lo que perturba el festín son los ruidos en la puerta o la llegada de la despensera o señora. En el segundo grupo, estarían las medievales más conocidas, a la zaga del texto de Esopo: la de Juan Ruiz (donde se menciona, aunque no aparece, el gato), la del Libro de los gatos y la versión del Fabulario de Sebastián Mey, con su «gatazo rojo». 
que queda luego, atestiguada por Correas, es la de «ojo» / «abrojo». ${ }^{14} \mathrm{Sin}$ embargo, encontramos otras, como la de "souto / outro» (v. en n. 19). Incluso Samaniego buscará, en su versión dieciochesca, «El ratón de la corte y el del campo", una rima aliterativa y sonora, aunque más culta y menos resonante: «Reniego yo del queso, del tocino / y de quien busca gustos / entre los sobresaltos y los sustos».

Las versiones castellanas medievales más conocidas e importantes del cuento del ratón de campo y el ratón de ciudad son dos: el «Ensienplo del mur de Monferrando y del mur de Guadalfajara» del Libro de buen amor (estrs. 1370-1385) y el «Ensiemplo de los mures» del Libro de los gatos. La primera deriva, como muchas de las fábulas de Juan Ruiz, de Walter Anglicus, en concreto de su fábula núm. XII (Hervieux, 1970: II, 321); y puesto que el Libro de los gatos es traducción de las Fabulae del predicador inglés Odo de Cheriton, la versión del Libro de los gatos deriva en concreto de la fábula XVI, "De mure domestica et silvestri vel campestri» (Hervieux 1970: IV, 190; Darbord, 1984).

Recordemos los dos versos finales, en refrán, de la magnífica versión de Juan Ruiz, el Arcipreste de Hita, puesto en boca del ratón de Monferrando:

Más quiero roer fava, seguro e en paz, que comer mil manjares, corrido e sin solaz. $(1381 a b)^{15}$

Final ratificado - como Celestina ratifica las palabras de Areúsa- por doña Garoça, en boca de quien ha sido contada la fábula esópica de Juan Ruiz, cuatro estrofas más adelante:

\section{Más vale en convento las sardinas saladas / ... / \\ que perder la mi alma con perdizes assadas. (1385a-c)}

Y podemos comparar ambos pareados con las conclusiones de Areúsa, primero, y las palabras de Celestina, a continuación. Observemos las equivalencias en el plano formal:

14.- Para Chevalier (1999: 90-91) resulta claro que «el texto de Francisco Santos, muy lejos de derivarse de Horacio o de Esopo, se apoya en un relato tradicional cuya conclusión se había hecho proverbial en la España del Siglo de Oro». Para la rima «ojo» / «abrojo» atestigua una versión vallisoletana, inédita, con fórmula: «Mejor quiero comer pajas de rastrojo que no verme con el pellejo encima de los ojos». Y, además, tres mejicanas: "Vale más entre espinas y abrojos que no con capillaje [o tapojos, o capiruzas] en los ojos».

15.- Véase, a propósito de las fábulas en el Libro de buen amor, sin ánimo de exhaustividad, Lecoy (1938), Morreale (1963, 2002), Lida de Malkiel (1976), Marmo (1983), Rodríguez Adrados (1986), Gybbon-Monnypenny (1988), Joset (1990). Más recientemente, Lacarra (1998), Morros $(2002,2003)$, Beltrán $(2005,2013)$ y Cuesta (2008a, 2008b). La fábula del «mur de Monferrando y el mur de Guadalajara» ha sido estudiada al detalle, en especial en sus aspectos lingüísticos, y en concreto en relación con la versión del Libro de los gatos, por Salvador Plans (1994); en el contexto de las fábulas del episodio de doña Garoza (LBA, 1332-1507), ha sido analizada por Morros (2003). 


\section{Libro de Buen amor}

Más quiero roer fava, seguro e en paz,

que comer mil manjares, corrido e sin solaz

\section{$1^{\circ}$ periodo:}

Sujeto elíptico en $1^{a}$ persona sing. + adv. de cantidad («más») + verbo "querer» + inf. (roer, vivir $)+\mathrm{OD} / \mathrm{CC}+$ dos adjetivos coordinados, apuestos al sujeto.

\section{$2^{\circ}$ periodo:}

«que» + infinitivo (presente o ausente, en zeugma) + OD / CC (sintagma con adjetivo ponderativo + sust. $)+$ dos adjetivos coordinados, apuestos al sujeto.

En el plano del contenido, los adjetivos apuestos dan la clave de lo que hay de común y de diferente entre ambos textos. El «mur de Monferrando" de Juan Ruiz está contraponiendo adjetivos relacionados con la seguridad y la estabilidad: prefiere estar "seguro», «en paz», a encontrarse en constante tensión ("corrido») e intranquilidad ("sin solaz»). Areúsa contrapone, por su parte, opuestos en el campo semántico de la libertad: dice preferir la total independencia ("esenta y señora») al encierro opresor ("sojuzgada y cativa»). La pareja de adjetivos apuestos va asociada, en el caso del "mur de Monferrando", a la rutinaria actividad propia y evidente de un roedor: "comer». La comida más sencilla (la «fava») se contrapone a la ostentosa y ponderada cuantitativamente («mil manjares»). En el caso de Areúsa, la actividad mencionada es más general («vivir») y lo que se contraponen son los habitáculos: «pequeña casa» frente a «ricos palacios». Por tanto, los términos relacionados con la alimentación están ausentes. Sin embargo, vamos a ver cómo los recoge Celestina:

\section{Libro de Buen amor}

\section{La Celestina}

Más vale en convento las sardinas saladas / ... / que vale más una migaja de pan con paz que perder la mi alma con perdizes assadas. que toda la casa llena de viandas con rencilla.

$1^{\circ}$ periodo:

Más vale/vale más + OD + complemento

$2^{\circ}$ periodo:

que + infinitivo (presente o elíptico) $+\mathrm{OD}+$ complemento

En los dos casos se transita en el campo semántico de la seguridad. Es decir, Celestina ignora la contraposición de Areúsa entre independencia y encierro; o, si no la ignora ni rechaza, sencillamente la traslada, como la fábula, al terreno de la estabilidad y la tranquilidad: "paz» y ausencia de «rencilla». Observemos que «paz» es un término que ya utilizaba el ratón de Monferrando (LBA, 1381a). Y Celestina incorpora definitivamente de manera plena la metáfora gastronómica: la "fava, seguro e en paz» o «las sardinas saladas», del LBA, pasan en boca de la alcahueta a «migaja 
de pan con paz»; y los "mil manjares» o "perdizes assadas» a "llena de viandas». La expresión "roer fava», en Juan Ruiz, viene directamente de la fuente latina ("rodere malo fabam quam cura perpete rodi», en Walter Anglicus), ${ }^{16}$ pero tiene la suficiente fuerza y garra como para servir de desenlace cómico. ${ }^{17}$

Desde luego, hay que poner en relación ese desenlace, esa rima y la misma estructura de la paremia («mejor es...», melius est...), además, con los latinajos con los que se consolaban los estudiantes del siglo XVI, tal y como nos reflejan los Coloquios de Palatino y Pinciano, donde dice uno de los dialogantes, Octaviano (y reparemos en la frase última):

Si el pan es duro, dicen al Bachiller: Domine, dic ut lapides isti panes fiant; si la porción es chica, dicen: Annihilata est portio mea, y prueban a echarla del plato a soplos, y si la echan, dicen: Memento mei, Deus, quia ventus est vita mea... [...] Con esta buena conversación pasan su mala ventura y entretienen y regocijan su comida y consuélanse diciendo: Melius est pusillum panis cum gaudio quam plena utraque manus cum taedio". (Chevalier, 1978: 121) ${ }^{18}$

El final del cuento, tanto en el $L B A$ como en estas versiones escolares, sería más insulso sin ese reconocimiento desvergonzado y ridículo de humana cobardía, con ese estribillo último a modo de "fórmula» típica del final de muchos cuentos, que tiene un efecto distorsionador sobre el decoro supuesto a los personajes. Ya sea por su vulgaridad («roer la fava»), ya por todo lo contrario, es decir, por su pretendida solemnidad altisonante: "panis cum gaudio... manus cum taedio".

Por tanto, y en una primera conclusión, el trasvase que tiene que hacer Celestina desde lo que escucha de Areúsa ( $H$ He querido más vivir en mi pequeña casa, esenta y señora, que no en sus ricos palacios, sojuzgada y cativa») hasta lo que confirma y ratifica, pero introduciendo las variantes gastronómicas ("que vale más una migaja de pan con paz que toda la casa llena de viandas con rencilla»), está muy probablemente motivado por-

16.- Cfr. Joan Corominas, ed., Libro de buen amor, Gredos, Madrid, 1967, p. 518. Sigo, sin embargo, para las citas del LBA, la ed. de Alberto Blecua (1992).

17.- Todo ello, independientemente de entrar en el campo de las connotaciones, en este caso claras correspondencias con "los recelos de la monja ante los placeres eróticos que la alcahueta le propone para tentarla. [Pues] Las comidas son metáforas del amor» (Zahareas y Pereira, 1990: 393).

18.- Una versión valenciana del cuento acaba con las siguientes palabras del ratón: «val més ser ratis flaquis en campis rasis, que no ser ratis grossis en boquis tortis de gatis pardis» (Beltrán, 2007: 568-570). En la versión asturiana recogida por Suárez (1998: nº 10), la fórmula final es la siguiente: «ivale más tar flaco nel souto que gordo na barriga doutro». Destaca igualmente la oposición flaco / gordo y la alusión a la barriga (en vez de la boca, en la versión valenciana). Los consuelos pícaros estudiantiles, del tipo del citado «panis cum gaudio ... melius quam ... manus cum taedio", sin duda expanden sus ecos hacia estas versiones populares. 
que las palabras de Areúsa le han recordado a la vieja una paremia o un refrán que viene al caso, y que pronuncia — despojado de la rima- como sentencia o proverbio.

No es muy rebuscado suponer que los ecos de esas paremias (en refrán o sin refrán: «paz» / «solaz», «paz» / «rencilla», «saladas» / "assadas»), con la fábula de los dos ratones tras de sí, ya estarían también reverberando en el monólogo de Areúsa. En mi opinión, Areúsa pretende identificarse con el simbolismo del ratón de campo que cuenta su aventura urbana, cuando vuelca en su parlamento, de manera visceral y torrencial, una experiencia del pasado de la que muy probablemente — como el mur de Monferrando- ha salido, ya que no trasquilada, sí traumatizada y bien escarmentada. Areúsa relata esa experiencia, naturalmente, como lo hace el enunciante externo de la fábula, fiel al espíritu aleccionador del género, es decir, para que sirva a su vez de escarmiento al auditorio. Es en ese sentido, además, en el que se podría especular algo más sobre el posible pasado urbano o en "palacio» del que habla Areúsa.

\section{Areúsa y su posible pasado en "palacio»}

Partiendo de que amancebamiento y prostitución pública son dos cosas muy distintas, Bienvenido Morros ha puntualizado que Areúsa es en la Comedia la mantenida o amancebada de un militar de carrera discreta, su "amigo" (el que menciona en el autor vi que se ha ido a la guerra), aunque luego la Tragicomedia la transforme en una prostituta, como Elicia. Areúsa "afirma y reitera que es mujer de un solo hombre al que no piensa traicionar para no perder los privilegios que ha conseguido al servirlo en su propia casa como si fuera realmente su esposa» (Morros, 2010: 361).

Pero Morros, yendo más allá de esa puntualización, plantea la posibilidad de que Areúsa hubiese sido criada de Melibea (2010: 371-373). Recordemos que Areúsa desvela a principios del mismo auto IX intimidades sobre la hija de Pleberio, aunque en muchas de sus afirmaciones parece obvio que exagera, tratando de ridiculizarla cuando habla de sus afeites, de sus pechos - como calabazas-, de un vientre que le parece adivinar — sin haberlo visto- fláccido. En los Remedia amoris ovidianos — señala Morros- hay referencias a las criadas que descubren a sus señoras recién levantadas, sin haberse quitado sus malolientes pringues, y se ríen de ellas cuando las sorprenden así:

Éste podría haber sido el caso de Areúsa, que habría sido testigo de las intimidades de Melibea por haberla servido anteriormente como criada. [...] De este modo se entendería que poco después de revelar esos detalles de la dama en cuya casa habría podido servir, se vana- 
gloriara de la independencia de la que ha gozado desde que tiene uso de razón compadeciendo a las criadas que son objeto de las arbitrariedades de sus señoras. Este discurso lo pronuncia mientras Lucrecia, la actual criada de Melibea, espera a que le abran la puerta después de haber llamado a ella. Concluye su intervención diciendo que prefiere "mas vivir en mi pequeña casa, exenta ["iibre'] y señora, que no en los ricos palacios de los grandes señores "sojuzgada y cautiva». [...] Si pondera no estar bajo el yugo de nadie es porque ese amigo no le exige ningún tipo de trabajo doméstico, que en eso solían diferenciarse las criadas de las mancebas. [...] Areúsa [...] habría empezado sirviendo en casa de Pleberio para después, harta de las arbitrariedades de Alisa, iniciar una relación estable cohabitando con ese amigo que se ha marchado a la guerra con su capitán. [...] En la Comedia, Rojas ha elegido ese currículo laboral para un personaje al que en la Tragicomedia otorgará un papel más decisivo en el desarrollo de la acción. El personaje cambia radicalmente de una versión a otra. (Morros, 2010: 372)

No es necesario, desde luego, compartir las sugerencias de Morros sobre la posibilidad de que Areúsa hubiese sido criada en la casa de Alisa para aceptar la huella de la fábula del ratón de campo. Pero su propuesta no sólo entra en sintonía con esa posibilidad, sino que le otorga, en mi opinión, un sentido mucho más profundo y una mayor coherencia.

Areúsa, como el ratón de campo, habla de una experiencia que pudo haber sido traumática en el pasado. Gilman ya anotaba como principal característica de Areúsa «su profundo rechazo sentimental de las formas legítimas de vida que la sociedad de su época le ofrecía a una joven de su clase social» (1974: 105). Areúsa habla con conocimiento de causa de lo que les ocurre a las criadas de casa burguesa o noble, que sufren engañadas: «denostadas, maltratadas las traen, continuo sojuzgadas». Y de ahí su rabia irrefrenable, que nada tiene que ver con el airado furor de Melibea. Una Areúsa que tal vez aluda tácitamente a su biografía personal constata que la única obligación que tienen las señoras con sus criadas, basada en los nexos de fidelidad y familiaridad que vinculan a ama y criada, es cruelmente incumplida: «Y cuando ven cerca el tiempo de la obligación de casalles, levántanles un caramillo...»; es decir, 'se inventan un chisme, un enredo, una excusa'. La conclusión es que, como toda recompensa por el servicio cumplido, "danles un ciento de azotes y échanlas la puerta fuera».

Areúsa cuenta su experiencia como se cuenta un relato de supervivencia. La experiencia de la esclava liberada, aliviada tras un encierro cruel, salvada de un naufragio vital. Y la cuenta haciendo expresivo, a la vez 
que el odio personal - y de clase-, un rechazo, un asco y una repulsión que unen lo gastronómico y lo social (Palafox, 2007; 2008: 70). Como en tantas fábulas que inciden persistentemente en los motivos de la posesión, el robo, el engaño, el ingenio, la venganza, la recompensa, etc., y siempre en torno a la comida, el monólogo de Areúsa se convierte, así, en la narración visualizada (escenificada) de un caso ejemplar — animal- de instinto de supervivencia.

El de la comida no es, desde luego, un monotema en el soliloquio de Areúsa. Sin embargo, empieza hablando de comida, en la hipotética conversación con sus "parientas» e "iguales»: “¿Qué cenaste? [...] ¿Cuántas gallinas crías? Llévame a merendar a tu casa»; y acaba también introduciendo elementos culinarios en los insultos de la señora, que acaban circularmente con la "gallina»:

"¿Por qué comiste esto, golosa?», "¿Cómo fregaste la sartén, puerca?» [...] "Quién perdió el plato, desaliñada?», "Cómo faltó el paño de manos, ladrona? A tu rufián le habrás dado». "Ven acá, mala mujer, cla gallina habada no parece?...».

Ya hemos comentado cómo el motivo de la pérdida de la gallina se abre, respecto al soliloquio del Arcipreste de Talavera, a una pluralidad de perspectivas, puesto que es vista no sólo desde el punto de la acusadora, sino también desde el de la acusada.

Podría pensarse, en fin, en una referencia más general, no a esa fábula del ratón campesino y urbano en particular, sino a otros cuentos o fábulas con parecido tratamiento argumental. De hecho, de no existir una identidad tan evidente entre las sentencias de Areúsa y Celestina y el refrán de la fábula, cabría la posibilidad de relativizar su huella. Ninguna fábula hay, desde luego, con el mismo remate final, es decir con los elementos convergentes del refrán. Y, sin embargo, el cotejo, antes de acabar, de otra fábula de tema semejante, nos permitirá ahondar en el planteamiento de esa posibilidad de ampliación, si bien para concluir descartándola.

La lección de libertad es incluso más diáfana que en la del ratón de campo en el cuento 245 (146), "El lobo, el perro y el collar», del Libro de los exemplos por A.B.C. de Clemente Sánchez, que lleva por título LIBERTAS NON POTEST AURO COMPARARI. Se traza en él, a modo de fábula, un diseño sobre un tema parecido al de los dos ratones, el del precio de la libertad, pero con un lobo y un perro de protagonistas. El lobo delgado prefiere la libertad a la comida abundante que disfruta un grueso perro, al observar la cadena que luce al cuello, que se revelará yugo opresor. En ese sentido, se trataría de una variante de la oposición entre vida humilde, pero libre, frente a vida acomodada, pero rodeada de peligros que «sojuzgan». La fábula dice así: 


\section{LIBERTAS NON POTEST AURO COMPARARI}

\section{No se puede comprar por oro nin plata la libertad; non ha cossa que a libertad sea comparada.}

Dizen en las fabrillas de los poetas un noble e notable enxemplo, seyendo espiritualmente entendido, que un lobo falló un can en el monte, e veyéndole muy gruesso, preguntole onde avía vevido, e dixo que en cassa de tal señor onde del pan de aquel estava gruesso. E rogole el lobo que lo levasse consigo, si podiesse ser que comiesse él assí bien como él, e plogo al can e levolo consigo. E yendo su camino vio el lobo como el cuello del can estava pelado. E dixo el lobo al can: - Amigo, ¿qué cosa es que tienes el cuello pelado?

E dixo el can: - Porque de día estó preso en cadena.

E dixo el lobo: - Yo non quiero por poco pan perder mi libertad.

E assí dexolo e fizo estos versos:

Non bene pro toto libertas venditur auro:

Hoc celeste domum preterit orbi sopes.

Por todo el oro mal se vende la libertad:

más que las riquezas val este don celestial.

(Sánchez, 2011: 131-133)

La versión-fuente que ofrece Walter Anglicus de esta fábula va encabezada por la sentencia que funciona como título y lema: Libertas non potest auro comparari. Juan Ruiz no la incluye entre las suyas del Libro de buen amor, pero sí que la conocería, con toda probabilidad, teniendo en cuenta que Gualterio el Inglés fue fuente de varias de sus fábulas, pero, sobre todo, que cita precisamente esa misma sentencia para ilustrar el final del «Enxienplo de las ranas en cómo demandavan rey a Don Júpiter» (LBA, 199-206): «Libertat e soltura non es por oro comprado (206d). ${ }^{19}$

Como hemos comentado, la lección de libertad es más clara en esta fábula que en la de los dos ratones. Mientras en ésta, con la resignación bucólica del animalillo a vivir en la mediocritas, la solución final que se ofrece contiene una lección que podría entenderse como de «cínico conformismo» (como lo define Baranda, 2004), aquí no hay ningún tipo de ambigüedad: el lobo apuesta claramente por la libertad y denigra la escla-

19.- Para Cuartero (2004: 226-227), la interferencia de la sentencia o paremia vendría del conocimiento por parte de Juan Ruiz del Compendium moralium notabilium del juez y humanista paduano Geremia de Montagnone (c. 1255-1321), una obra de referencia, que le permitiría al Arcipreste de Hita la localización de diversas fuentes y que ya incluye unidos los dos motivos principales que en principio proceden de orígenes distintos — la fábula «De ranis et hydro» y la paremia de la fábula "De cane et lupo». 
vitud. Sin embargo, observemos que la constatación de que la libertad es mejor que cualquier opresión viene por la simple observación de la herida producida por el collar, pero no por una experiencia vital que confirme en carne propia el lobo, como observador del yugo dominador, y que haga más vívida la inexorabilidad de su decisión de mantenerse libre. La fábula no es, en definitiva, ni tan dinámica ni tan empática como la de los dos ratones. Es más una lección sentenciosa desplegada como diálogo que un relato concentrado, verosímil dentro de las leyes del género del cuento de animales, al que se pueda aplicar una moral final.

El cuento-tipo ATU, 201 (The Lean Dog Prefers Liberty to Abundant Food and a Chain), al que corresponde la fábula, no está incluido en el catálogo de Camarena-Chevalier (1997), por lo que no parece que se hayan registrado otras versiones tradicionales españolas de ella, aunque Hernández Fernández (2005; 2013) recoge excepcionalmente una en Mula (Murcia), de probable origen literario. ${ }^{20}$

El hecho de que pueda considerarse el tema de esta fábula, al menos en la tradición hispánica, como una variante del tema del ratón de campo y el de ciudad en el sentido de que "es preferible una vida tranquila y en libertad, a otra rica y acomodada pero rodeada de peligros e inquietudes» (Hernández, 2013: 73), nos lleva a entender que los campos de la libertad (Areúsa) y la tranquilidad o conformidad (Celestina) de alguna manera se neutralizan. Aunque nosotros tendemos a concentrar en el lexema libertad el único antónimo posible de la opresión y el «sojuzgamiento» que describe Areúsa, ella no está hablando estrictamente de libertad, como tampoco presenta la situación de servidumbre de las "criadas» como una situación de esclavitud (como la que simbolizaría el icono del collar del perro en la fábula). Areúsa habla, más que de libertad, de independencia: de ser "señora y esenta». Y "esenta», que se traduce en los glosarios como 'libre', literalmente significa 'sola, apartada, independiente'. Como Morros acota para el pasaje entero:

Esta extensa intervención de Areúsa no sólo debe interpretarse como una crítica - apoyada por cierto sentimiento de igualdad y de independencia- contra la conducta adoptada en la época por las señoras para con sus criadas (y en coincidencia con los consejos de Celestina a Pármeno [en I, x]), sino también como un alarde de la situación económica - muy desahogada - en que vive la prostituta y que le confiere una total independencia gracias a la práctica clandestina de su oficio. (Morros, 1996: 188, n. 22)

20.- Rodríguez Adrados (1986) la documenta en la Antigüedad greco-latina: H294 (=M96). Aparece en Fedro, III-7, Babrio, 100 (Perry, 1965) y Aviano, XXXVII (en éste los protagonistas son un perro y un león). 
Areúsa presume de esa independencia social, laboral, acompañada - sin contradicción alguna- de mediocridad "conformista», y describe orgullosa el proceso que le ha conducido a tal independencia, abominando y execrando lo que pudo haber sido su destino de haber continuado - cual ratón de ciudad en rico palacio- al servicio de señoras inclementes. No son aspectos antitéticos, por tanto, el de la independencia y la apacible mediocritas, sino perfectamente armónicos, como en el ideal moderno de comodidad burguesa. Areúsa, satisfecha más que resignada, reconoce y constata que los grandes «placeres» o anhelos a los que pudo en un tiempo aspirar, ya no son asequibles. No lo son para ella, que superó aquella difícil etapa vital, ni lo deberían ser para las de su clase, las "criadas» de su monólogo. Fueron y son, viene a decir, ilusiones vanas, como las de la quimera del ratón de ciudad intentando vivir cómodamente, pero con el constante peligro de una espada de Damocles pendiendo encima de su cabeza. Las «señoras», como la gata de la fábula, son una peligrosa amenaza, eternamente al acecho, que convendrá sortear cuanto antes. De manera que, además de ejercicios de vanidad inútiles, serán peligrosos los intentos de jovencitas e inexpertas como Lucrecia para amoldarse a sus deseos y caprichos, tan naturales e irremediables como crueles y peligrosos.

\section{Bibliografía citada}

Ariza Viguera, Manuel (2003), «Lo oral en lo escrito: el Arcipreste de Talavera», en Homenaje al profesor Estanislao Ramón Trives, Murcia, Univ. de Murcia, pp. 103-122.

ATU: véase Uther (2004).

BARANDA, Consolación (2004), "La Celestina» y el mundo como conflicto, Salamanca, Univ. de Salamanca.

Beltrán, Rafael (1997), "Eliseu (Tirant lo Blanc) ante el espejo de Lucrecia (la Celestina): retrato de la doncella como cómplice fiel del amor secreto", en Cinco siglos de Celestina: aportaciones interpretativas, ed. J. L. Canet y R. Beltrán, Valencia, Publicacions de la Universitat de València, 1997, pp. 15-41.

(2005), "Cuentos populares del Libro de buen amor en la tradición oral moderna, I (las fábulas): pérdidas, pervivencias y irecuperaciones?», en Actas del IX Congreso Internacional de la Asociación Hispánica de Literatura Medieval (A Coruña, 18-22 de septiembre de 2001), ed. Carmen Parrilla y Mercedes Pampín, Noia (A Coruña), Universidade da Coruña - Ed. Toxosoutos, 3 vols. vol. I, pp. 455-478. 
Beltrán, Rafael (2007), Rondalles populars valencianes. Antologia, catàleg $i$ estudi dins la tradició del folklore universal, Valencia, Univ. de València.

(2013), «juan Ruiz, folclorista? Un posible nuevo cuento (ATU, 1381B) escondido en el Libro de buen amor", en Two Spanish Masterpieces. A Celebration of the Life and Work of Maria Rosa Lida de Malkiel, ed. Pablo Ancos y Ivy A. Corfis, Nueva York, Hispanic Seminary of Medieval Studies, 2013, pp. 113-139.

Blay Manzanera, Vicenta y Dorothy S. Severin (1999), Animals in "Celestina", Londres, Queen Mary \& Westfield College.

Blecua, Alberto, ed. (1992), Juan Ruiz, Arcipreste de Hita, Libro de buen amor, Madrid, Cátedra.

Bustos Tovar, José Jesús (2001), «De la oralidad a la escritura en la transición de la Edad Media al Renacimiento: la textualización del diálogo conversacional», Criticón, 81-82, pp. 191-206.

Camarena Laucirica, Julio y Maxime Chevalier (1997), Catálogo Tipológico del Cuento Folklórico Español. Cuentos de animales, Madrid, Gredos.

Canet, José Luis, ed. (2011), Comedia de Calisto y Melibea, 'Textos Parnaseo', 14, Valencia, Publicacions de la Universitat de València.

CAZAL, Françoise (1997), "Gatos y gatas en el Vocabulario de refranes y frases proverbiales de Gonzalo de Correas (1627)», Criticón, 71, pp. 33-52.

Chevalier, Maxime (1976), "La Celestina según sus lectores», en Lectura y lectores en la España del siglo XVI y XVII, Madrid, Turner, pp. 138-166.

(1978), Folklore y literatura: el cuento oral en el Siglo de Oro, Barcelona, Crítica.

(1999), Cuento tradicional, cultura literaria (siglos XVI-XIX), Salamanca, Univ. de Salamanca.

Cuartero Sancho, M. del Pilar (2004), "La paremiología en el Libro de buen amor», en Juan Ruiz, Arcipreste de Hita y el "Libro de buen amor». Congreso Internacional del Centro para la Edición de los Clásicos Españoles (Alcalá la Real, 9-11 de Mayo del 2002), eds. Bienvenido Morros y Francisco Toro, Alcalá la Real, Ayuntamiento de Alcalá la Real, pp. 215-234.

Cuesta Torre, María Luzdivina (2008a), "Los caballeros y don Amor: una aproximación a la imagen de la caballería en el Libro de buen amor», en Juan Ruiz, Arcipreste de Hita y el "Libro de buen amor»: Congreso Homenaje a Alan Deyermond, eds. Louise Haywood y Francisco Toro, Ayuntamiento de Alcalá la Real, Alcalá la Real,pp. 129-140.

, (2008b), «El ensiemplo del león y del caballo y la crítica a la caballería en el Libro de buen amor», Boletín de la Biblioteca Menéndez Pelayo, 84, pp.109-133.

DARborD, Bernard, ed. (1984), Libro de los gatos, 'Annexes des Cahiers de Linguistique Hispanique Médiévale', 3, París, Klincksieck.

De Miguel Martínez, Emilio (1996), La "Celestina» de Rojas, Madrid, Gredos. 
Eaton, Katherine (1973), "The Character of Lucrecia in La Celestina», Annali dell'Istituto Orientali di Napoli-Sezione Romanza, 15, pp. 213-225.

Franchini, Enzo (2001), Los debates literarios en la Edad Media, Madrid, Laberinto.

García Yero, Olga (2003), «Mujer y participación en La Celestina», Revista Antenas, 10, pp. 29-32.

Gilman, Stephen (1974), "La Celestina». Arte y estructura. Madrid, Taurus.

Gybbon-Monnypenny, G. B., ed. (1988), Juan Ruiz, Libro de buen amor, Madrid, Castalia, 1988.

HeRNÁNDEZ FeRNÁNDEZ, Ángel (2005), «Literatura y tradición oral: fábulas y cuentos de animales (I)», Revista de Folklore, 299, pp. 158-176.

- (2013), Catálogo tipológico del cuento folclórico en Murcia. 'El Jardín de la voz (Biblioteca de Literatura Oral y Cultura Popular)', 13, Universidad de Alcalá-UNAM-Centro de Estudios Cervantinos.

Hervieux, Léopold, ed., Les Fabulistes latins, depuis le siècle d'Auguste jusqu'à la fin du Moyen Âge. Vol. 2, Phèdre et ses anciens imitateurs directs et indirects, II, Paris, Firmin- Didot, 1893-1899. 5 vols. [Reimp. Hildesheim, Georg Olms, 1970.]

Joset, Jacques, ed. (1990), Juan Ruiz, Arcipreste de Hita, Libro de buen amor, Madrid, Taurus.

LaCarra, Mª Eugenia (1990), Cómo leer "La Celestina», Madrid-Gijón, Júcar.

LACARRA, M. ${ }^{a}$ Jesús (1998), «El Libro de buen amor, ejemplario de fábulas a lo profano", Juan Paredes y Paloma Gracia, eds. Tipología de las formas narrativas breves románicas medievales, Granada, Universidad de Granada, pp. 237-252.

LeCoy, Félix (1938), Recherches sur le "Libro de buen amor» de Juan Ruiz, Archiprêtre de Hita, París, Droz, 1938. [Reedición, ampliada por A. D. Deyermond, Farnborough, Gregg International, 1974.]

Lida de Malkiel, María Rosa (1966), Dos obras maestras españolas: el "Libro de buen amor" y "La Celestina». Buenos Aires: Eudeba.

- (1976), El cuento popular y otros ensayos, Buenos Aires, Losada.

Maravall, José Antonio (1981), El mundo social de "La Celestina", Madrid, Gredos.

Marmo, V. (1983), Dalle fonti alle forme. Studi sul "Libro de buen amor», Nápoles, Liguori.

Michael, Ian (1970), "The function of the popular tale in the Libro de buen amor», en "Libro de buen amor» Studies, ed. G. B. Gybbon-Monypenny, Londres, Tamesis, pp. 177-218.

Morreale, Margherita (1963), "Apuntes para un comentario literal del $L i-$ bro de buen amor», Boletín de la Real Academia Española, XLIII, pp. 249-371.

- (2002), "La fábula en la Edad Media: el Libro de Juan Ruiz como representante castellano del Isopete», en Y así dijo la zorra. La tradición fabulística en los pueblos del Mediterráneo, eds. Aurelio Pérez Jiménez y Gonzalo Cruz Andreotti, Madrid, Ediciones Clásicas, 2002, pp. 209-238. 
Morros, Bienvenido (2010), "Areúsa en La Celestina: de la Comedia a la Tragicomedia", Anuario de Estudios Medievales, 40, pp. 355-385.

Palafox, Eloísa (2007), "†iTanto nos diessen del paraýso quando allá vamos!': la retórica de la comida en la Tragicomedia de Calisto y Melibea", Revista Canadiense de Estudios Hispánicos, 32, pp. 71-88.

- (2008), «'E yo tomava aquella masa en escuso e fazíala pan’: el lugar de la comida en el exemplum medieval, el caso del Sendebar castellano", Memorabilia, 11, pp. 65-80.

Parrilla, Carmen (1999), "Leyendo a Areúsa», Ínsula, 633, pp. 18-19.

Perry, Ben Edwin, ed. (1965), Babrius and Phaedrus, Cambridge (Mass.)Londres, Harvard Univ. Press-William Heinemann.

Refael-Vivante, Revital (2009), "Entre el ratón y la rata en las fábulas hebreas de la Edad Media», eHumanista, 12, pp. 269-290.

Rodríguez Adrados, Francisco (1986), "Aportaciones al estudio de las fuentes de las fábulas del Arcipreste», en Philologia Hispaniensia in Honorem Manuel Alvar, Madrid, Gredos, 3 vols., vol. 3, pp. 459-473.

RojAs, Fernando de (1991), Comedia o Tragicomedia de Calisto y Melibea, ed. Peter E. Russell, Madrid, Castalia.

RoJAS, Fernando de (1995), La Celestina, ed. Dorothy S. Severin, Madrid, Cátedra.

Rojas, Fernando de (1996), La Celestina, ed. Bienvenido Morros, Barcelona, Vicens Vives.

RojAS, Fernando de (y "antiguo autor») (2011), La Celestina. Tragicomedia de Calisto y Melibea, ed. F. J. Lobera, G. Serés, P. Díaz-Mas, C. Mota e I. Ruiz Arzálluz, y F. Rico, Barcelona, Galaxia Gutenberg / Círculo de Lectores.

Salvador Plans, Antonio (1994), "Tradición y originalidad en el cuento medieval español: la fábula de los dos mures», Anuario de estudios filológicos, 17, pp. 395-414.

- (2007), "El episodio de la pérdida del huevo y la gallina», Anuario de estudios filológicos, 30, pp. 335-352.

SánCHEZ, Clemente (2011), Libro de los exemplos por A.B.C. ( $2^{\mathrm{a}}$ parte), ed. M. ${ }^{a}$ del Mar Gutiérrez Martínez, Memorabilia, 13, pp. 1-216.

[Dr. Castro] Seniloquium. Refranes que dizen los viejos (2004), ed., trad. y notas de Fernando Cantalapiedra y Juan Moreno, Anexos de la Revista Lemir, pp. 27-242.

Serés, Guillermo (2007), "Menéndez Pelayo y La Celestina», en Orígenes de la novela: estudios, ed. Raquel Gutiérrez Sebastián y Borja Gutiérrez Gutiérrez, Santander, Universidad de Cantabria / Sociedad Menéndez Pelayo, pp. 381-406.

SuÁrez López, Jesús. Cuentos del Siglo de Oro en la tradición oral de Asturias. Gijón, Ayuntamiento, 1998. 
UtHer, Hans-Jörg (2004), The Types of International Folktales. A Classification and Bibliography. Based on the System of Antti Aarne and Stith Thompson. Helsinki: Suomalainen Tiedeakatemia - Academia Scientiarum Fennica, 3 vols. [ATU]

Zahareas, Anthony N. y Oscar Pereira (1990), Itinerario del "Libro del Arcipreste»: Glosas críticas al "Libro de buen amor», Madison, Hispanic Seminary of Medieval Studies. 


\title{
Beltrán LlaVAdor, Rafael, "La fábula del ratón de campo y el ratón de ciudad y el monólogo de Areúsa sobre la vida de las criadas», Celestinesca 38 (2014), pp. 11-36.
}

\section{RESUMEN}

Este artículo trata de presentar algunas posibles huellas de la fábula del ratón de campo y el ratón de ciudad (ATU, 112: Country Mouse Visits Town Mouse), en el monólogo de Areúsa sobre la vida de las criadas, que se da al final de la segunda escena del noveno auto de La Celestina. Se estudia el monólogo, los ecos de la conclusión de varias versiones latinas y vernáculas de la fábula, muy conocida en la Edad Media. Y se propone que Areúsa identifica su pasado en "palacio» (como el de ratón de ciudad) y su presente, más humilde, pero también más libre.

PAlabras Clave: Celestina, Areúsa, monólogo, cuento, fábula.

\begin{abstract}
This article aims to present some possible traces of the folktale Country Mouse Visits Town Mouse (ATU, 112) in Areúsa's monologue about the life of the maids, which appears at the end of the second scene of Auto IX in La Celestina. The articles examines the monologue and the echoes of several Latin and vernacular versions enclosed in this well-known folktale. It is suggested that Areúsa could seek an identification between her past life in "palace» (as the city mouse) and her humbler but freer existence in the present.
\end{abstract}

KEY WORDS: Celestina, Areúsa, monologue, folktale, fable.

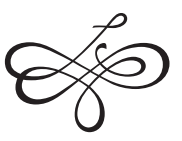

